\title{
Differences in Median Ultraviolet Light Transmissions of Serial Homeopathic Dilutions of Copper Sulfate, Hypericum perforatum, and Sulfur
}

\author{
Sabine D. Klein, ${ }^{1}$ Annegret Sandig, ${ }^{1}$ Stephan Baumgartner, ${ }^{1,2}$ and Ursula Wolf ${ }^{1}$ \\ ${ }^{1}$ Institute of Complementary Medicine (KIKOM), University of Bern, 3010 Bern, Switzerland \\ ${ }^{2}$ Society for Cancer Research, Hiscia Institute, 4144 Arlesheim, Switzerland \\ Correspondence should be addressed to Ursula Wolf, ursula.wolf@kikom.unibe.ch
}

Received 19 September 2012; Revised 20 November 2012; Accepted 23 November 2012

Academic Editor: Andreas Sandner-Kiesling

Copyright (C) 2013 Sabine D. Klein et al. This is an open access article distributed under the Creative Commons Attribution License, which permits unrestricted use, distribution, and reproduction in any medium, provided the original work is properly cited.

Homeopathic remedies are produced by potentising, that is, the serial logarithmic dilution and succussion of a mother tincture. Techniques like ultraviolet spectroscopy, nuclear magnetic resonance, calorimetry, or thermoluminescence have been used to investigate their physical properties. In this study, homeopathic centesimal (c) potencies (6c to 30c) of copper sulfate, Hypericum perforatum, and sulfur as well as succussed water controls were prepared. Samples of these preparations were exposed to external physical factors like heat, pressure, ultraviolet radiation, or electromagnetic fields to mimic possible everyday storage conditions. The median transmissions from $190 \mathrm{~nm}$ to $340 \mathrm{~nm}$ and $220 \mathrm{~nm}$ to $340 \mathrm{~nm}$ were determined by ultraviolet light spectroscopy on five measurement days distributed over several months. Transmissions of controls and potencies of sulfur differed significantly on two of five measurement days and after exposure to physical factors. Transmissions of potencies exposed to ultraviolet light and unexposed potencies of copper sulfate and Hypericum perforatum differed significantly. Potency levels $6 \mathrm{c}$ to $30 \mathrm{c}$ were also compared, and wavelike patterns of higher and lower transmissions were found. The Kruskal-Wallis test yielded significant differences for the potency levels of all three substances. Aiming at understanding the physical properties of homeopathic preparations, this study confirmed and expanded the findings of previous studies.

\section{Introduction}

Homeopathic preparations (hp) are used in complementary medicine worldwide, but homeopathy has been and is still vigorously debated [1-4], and these debates are based on prior believes [5]. While there seems to be good preclinical and clinical evidence for specific effects of hp [6-15], the underlying mode of action is yet unclear. Our aim is to determine potential physical properties of hp, which eventually may allow a scientific understanding of $\mathrm{hp}$.

Homeopathic remedies are produced by potentising, that is, the serial logarithmic dilution and succussion of a mother tincture. Several standard techniques of measuring physical properties of hp have been used in previous studies [16], including ultraviolet (UV) spectroscopy [17-24], nuclear magnetic resonance techniques [25-31], calorimetry [32], and thermoluminescence $[33,34]$.

In preceding studies, we observed significant differences in the transmission of UV light between $\mathrm{hp}$ and controls $[23,24]$, and between hp exposed to physical factors and unexposed $\mathrm{hp}$ [23]. The aim of the present study was (i) to target reproducing our results and (ii) to expand the nature of starting materials and external physical factors. We included a dilution of Hypericum perforatum, a plant often used in homeopathy, anthroposophically extended medicine, and phytotherapy. Since many questions about the stability of hp remain unsettled, for example, regarding storage conditions, sterilisation procedures, or exposure to radiation from mobile phones and scanners, we exposed $h p$ to elevated temperature, pressure in an autoclave, UV light, and non-ionising radiation. 


\section{Materials and Methods}

2.1. Materials. Hp were prepared from copper sulfate ( $\mathrm{CuSO}_{4}$; Weleda AG, Arlesheim, Switzerland), sublimed sulphur ( $\mathrm{S}_{8}$; Phytomed AG, Hasle/Burgdorf, Switzerland), and Hypericum perforatum alcoholic dilution mother tincture, $62 \%$ alcohol (hypericum; Herbamed AG, Bühler, Switzerland).

Cleaning of the vessels for potentisation, autoclavation and rinsing the tubes and cuvettes during the measurements was performed by using $18 \mathrm{M} \Omega$ distilled sterile water (purified water by Arium 61316 reverse Osmosis System, Satorius Stedim AG, Aubagne, France). For the preparation of controls and hp, $18 \mathrm{M} \Omega$ autoclaved distilled deionised water (Hiscia Institute, Arlesheim, Switzerland) was used, delivered in $10 \mathrm{~L}$ Schott Duran bottles (VWR International Dietikon, Switzerland).

All of the hp and controls were stored and potentised in $500 \mathrm{~mL}$ narrow necked bottles with standard ground joint and a conical shoulder, made from borosilicate glass with hydrolytic class 1 , that is, highly resistant against corrosion in neutral, basic, and acid environments (Schott Duran, VWR International Dietikon, Switzerland), closed with standard ground Duran flat-head stoppers.

Potentisation vessels and stoppers as well as UV measurement test tubes were reused from former experiments $[23,24]$. Preceding potentization all vessels were cleaned by rinsing three times with $18 \mathrm{M} \Omega$ water in order to decrease potential ion leaching from the vessel wall. The same procedure was applied to the test tubes used in the autosampler of the UV-spectrometer (see below). The process of cleaning, drying, and filling all vessels and test tubes was performed in a laboratory under laminar flow (Prettl GmbH, Pfullingen, Germany). The test tubes for UV measurements of the samples were $18 \mathrm{~mL}$ tubes, made from hydrolytic glass (Schott Fiolax, Mitterteich, Germany) and were filled with the homeopathic samples by one-way $20 \mathrm{~mL}$, sterile, polystyrene pipettes (Pipetboy acu, Integra Bioscience AG, Zizers, Switzerland).

2.2. Sample Preparation. The hp were prepared according to the legal regulation for homeopathic remedies [35] by using the multiple glass method. Potentisation was performed by hand through horizontally shaking the vessel at a rate of about $2.7 \mathrm{~Hz}$ for $4 \mathrm{~min}$ for $\mathrm{CuSO}_{4}$ and $\mathrm{S}_{8}$, and for $2.5 \mathrm{~min}$ for hypericum prior to each dilution step.

All hp were made as c preparations (i.e., centesimal potency means 100 -fold dilution with each step) up to $30 \mathrm{c}$. $\mathrm{CuSO}_{4}$ and hypericum had each 10 independent succussed water controls, while $S_{8}$ had 12 controls, prepared with each 5 (6) vessels before and 5 (6) after the potentisation process to examine possible cross contamination. Controls were produced by shaking the potentisation medium (water) at the same duration as the hp, but controls were not diluted.

All steps of preparation and handling with open vessels were performed under a laminar flow box wearing sterile examination gloves and a lab coat to prevent unwanted contamination of the samples. Vessels were shielded with aluminium foil and stored closed in boxes at stable temperature and humidity.

Computer-generated random codes were used for randomisation. Blinding of the vessels was performed by an unbiased person, lists of the allocation of contents to the vessels were kept closed until the end of data attainment and data reduction.

2.3. Exposure to External Physical Factors. Samples of hp and controls were exposed to one of the following external physical factors: (1) incubation (Incubator, Sauter, Switzerland) at $37^{\circ} \mathrm{C}$ for 24 hours, (2) UV light at $252 \mathrm{~nm}$ of a sterilisation lamp for 12 hours (CAMAG Reprostar, Switzerland), (3) heat under pressure by autoclave (Fedegari Autoclavi, Vitaris AG, Baar, Switzerland) at a temperature of $90^{\circ} \mathrm{C}$ for 20 minutes, filled into autoclavable Duran vessels (Schott Fiolax), or (4) an electromagnetic field of a mobile phone (Philips, Savvy Dual Band) at $900 \mathrm{MHz}$ with an output of $2 \mathrm{~W}$ for 120 minutes while the test tubes with samples were placed on a turning plate under the laminar flow.

2.4. UV Spectroscopy. Data were acquired by a Shimadzu UV PC 1650 spectrometer (Kyoto, Japan) with a wavelength range from 190 to $1100 \mathrm{~nm}$, equipped with an auto sampler CETAC ASX-260 (Omaha, USA), and a sipper.

Comprehensive preparatory measurements were achieved in previous investigations to identify the impact of instrumental parameters on reproducibility such as wavelength of lamp change from visible (VIS) to UV lamp and scan speed, instrumental drift, warm-up time, number of repetitions, sip and purge time. Prior to the measurements, a baseline calibration was completed with the cuvette filled with $18 \mathrm{M} \Omega$ water. Light transmission was measured from 190 to $1100 \mathrm{~nm}$. Each measurement was repeated four times with the first run including five samples of $18 \mathrm{M} \Omega$ water as a run-in before the actual samples. The unit of equipment was engaged 10 hours prior to actual measurements to achieve an efficient warm-up and to decrease the instrumental drift. Room temperature and humidity were kept constant. Heated samples were allowed to regain room temperature before the measurements.

Figure 1 shows the timeline of preparation of the samples and measurements.

2.5. Data Analysis. To compare measurements performed on different days, the common daily variations of a UV spectrophotometer that occur due to a new calibration on each measurement day had to be corrected for. Thus, transmissions of the samples (controls or hp) were divided by transmissions of the pooled controls for each day and wavelength $(\mathrm{nm})$.

Median transmission values were calculated for the ranges of $190 \mathrm{~nm}-340 \mathrm{~nm}$ and $220 \mathrm{~nm}-340 \mathrm{~nm}$ as in [23]. Since not all data were normally distributed, non-parametric tests (Mann-Whitney- $U$, Kruskal-Wallis and JonckheereTerpstra) were used to compare controls and hp on the same measurement day or hp on different measurement days. 


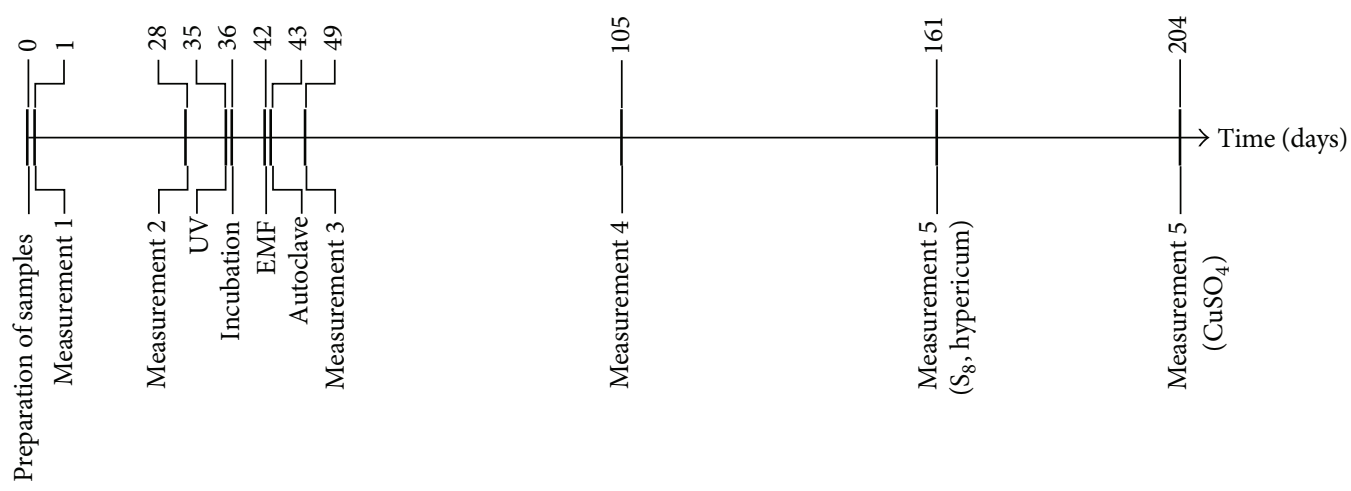

FIGURE 1: Timeline of preparation of the samples and measurements. After 34, 35, 41, and 42 days, samples of potencies and controls were either exposed to UV light (UV) for $12 \mathrm{~h}$, incubated at $37^{\circ} \mathrm{C}$ for $24 \mathrm{~h}$ (incubation), exposed to an electromagnetic field (EMF) for $2 \mathrm{~h}$, or incubated in an autoclave (autoclave) for $20 \mathrm{~min}$, respectively, and light transmission was measured the following day (days 35 , 36, 42, and 43 , resp.).

Effect sizes $(r)$ were calculated and results were reported according to [36].

In order to compare the present study to the previous ones performed by our group [23, 24], differences of means (transmission of controls - transmission of $\mathrm{hp}$ ) in \% and 95\% confidence intervals were calculated. All measurements of $\mathrm{CuSO}_{4}$ and of $\mathrm{S}_{8}$ were finally combined with the number of measurement days as weight.

SPSS Statistics 17.0 and 20.0 (IBM, Armonk, USA) was used for statistical analyses.

\section{Results}

3.1. Controls Prepared before and after the hp. When controls 1 (prepared before the series of potencies) and controls 2 (prepared after the series of potencies) were compared by Mann-Whitney- $U$ test, only in measurement 1 (of 5 ) of the $\mathrm{CuSO}_{4}$ measurements a statistically significant difference was found, but in none of the measurements of hypericum or $\mathrm{S}_{8}$. Therefore, it was concluded that the order of preparation did not have an effect on the transmissions measured, and, consequently, controls 1 and 2 for each substance were combined for further calculations.

3.2. Differences between Controls and $h p$. Controls and hp of each measurement day were compared separately. In unexposed samples, controls and hp differed significantly for $\mathrm{S}_{8}$ on measurement days 2 and 3 (Table 1). While controls of $\mathrm{CuSO}_{4}$ and hypericum tended to have higher transmissions than hp, controls of $S_{8}$ had lower transmissions than hp.

Controls and hp of samples exposed to physical factors showed significant differences in transmission for $\mathrm{CuSO}_{4}$ after incubation, for hypericum after exposure to UV, and for $\mathrm{S}_{8}$ after all of the 4 factors (Table 1). Both ranges of transmission (190 nm-340 nm and $220 \mathrm{~nm}-340 \mathrm{~nm}$ ) yielded similar results with respect to significant differences between groups.
3.3. Influence of Ageing. To investigate the possible influence of ageing on hp, measurements 1 to 5 of hp (without controls) were compared using a Kruskal-Wallis test. Significant differences between the 5 measurement days were found for $\mathrm{S}_{8}(190 \mathrm{~nm}-340 \mathrm{~nm}: P=0.002 ; 220 \mathrm{~nm}-340 \mathrm{~nm}: P=$ $0.004)$. Jonckheere's test revealed no significant trend in the data. For $\mathrm{CuSO}_{4}$ and hypericum, no differences between the measurement days were found.

3.4. Effect of Exposure to External Physical Factors. It was investigated whether exposure of the hp to external physical factors had an effect on transmission compared to nonexposed hp. For that purpose, non-exposed hp of measurements 2 and 3 were combined and compared to exposed hp (Table 2). Significant differences were found for $\mathrm{CuSO}_{4}$ after incubation and UV as well as for hypericum after UV, where transmissions of hp after exposure to these physical factors were reduced compared to transmissions of non-exposed hp. No significant changes have been observed for $S_{8}$.

3.5. Differences between Potency Levels. Potency levels $6 \mathrm{c}$ to $30 \mathrm{c}$ of non-exposed hp were also compared among one another. Figures 2(a), 2(b), and 2(c) show wavelike patterns of higher and lower transmissions for the dilutions of all 3 preparation series. Kruskal-Wallis tests yielded mostly significant differences for the potency levels $(190 \mathrm{~nm}-340 \mathrm{~nm}$ : $P\left(\mathrm{CuSO}_{4}\right)=0.032, P($ hypericum $)=0.008, P\left(\mathrm{~S}_{8}\right)=0.009$; $220 \mathrm{~nm}-340 \mathrm{~nm}: P\left(\mathrm{CuSO}_{4}\right)=0.051, P($ hypericum $)=0.014$, $\left.P\left(\mathrm{~S}_{8}\right)=0.012\right)$. Jonckheere's test showed a tendency towards ascending medians with ascending potency levels for $\mathrm{CuSO}_{4}$ $(190 \mathrm{~nm}-340 \mathrm{~nm}: P=0.080 ; 220 \mathrm{~nm}-340 \mathrm{~nm}: P=0.072)$ and a tendency towards descending medians for hypericum (190 nm-340 nm: $P=0.057 ; 220$ nm-340 nm: $P=0.065)$. A significant trend was revealed for $S_{8}$ with higher transmission values for higher potency levels $(190 \mathrm{~nm}-340 \mathrm{~nm}: P=0.015$, $z=2.425, r=0.222 ; 220 \mathrm{~nm}-340 \mathrm{~nm}: P=0.028, z=2.196$, $r=0.201)$. 
TABLE 1: Comparison ${ }^{\mathrm{a}}$ between light transmissions of controls ${ }^{\mathrm{b}}$ and potencies $(6 \mathrm{c}-30 \mathrm{c})^{\mathrm{c}}$ of $\mathrm{CuSO}_{4}$, hypericum, and $\mathrm{S}_{8}$.

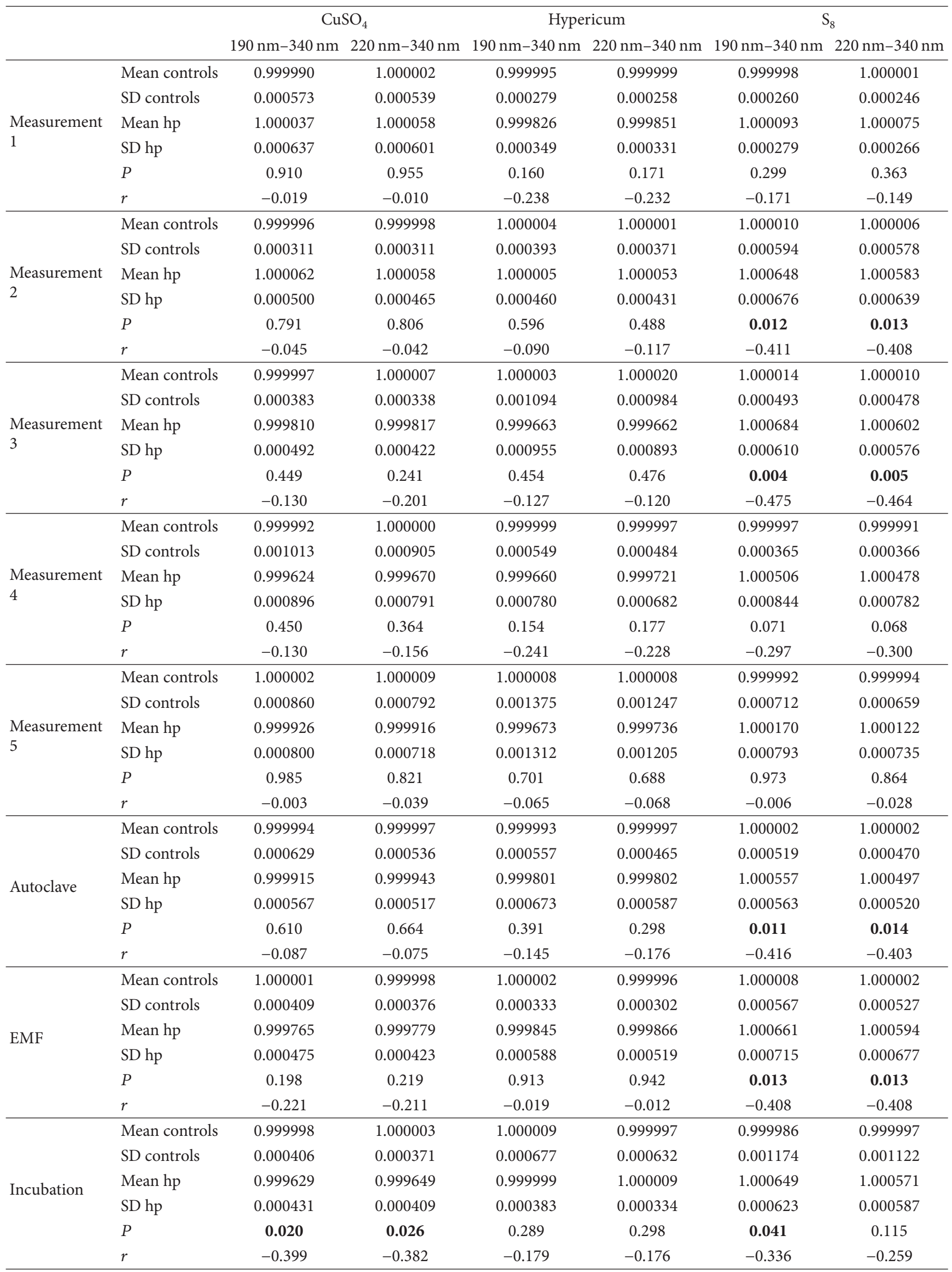


TABLE 1: Continued.

\begin{tabular}{|c|c|c|c|c|c|c|c|}
\hline & \multicolumn{2}{|c|}{$\mathrm{CuSO}_{4}$} & \multicolumn{2}{|c|}{ Hypericum } & \multicolumn{2}{|c|}{$\mathrm{S}_{8}$} \\
\hline & & $190 \mathrm{~nm}-340 \mathrm{~nm}$ & $220 \mathrm{~nm}-340 \mathrm{~nm}$ & $190 \mathrm{~nm}-340 \mathrm{~nm}$ & $220 \mathrm{~nm}-340 \mathrm{~nm}$ & $190 \mathrm{~nm}-340 \mathrm{~nm}$ & $220 \mathrm{~nm}-340 \mathrm{~nm}$ \\
\hline \multirow{6}{*}{ UV } & Mean controls & 1.000003 & 1.000005 & 1.000000 & 1.000000 & 1.000001 & 1.000009 \\
\hline & SD controls & 0.000629 & 0.000612 & 0.000580 & 0.000569 & 0.000439 & 0.000413 \\
\hline & Mean hp & 0.999610 & 0.999637 & 0.999558 & 0.999586 & 1.000676 & 1.000599 \\
\hline & SD hp & 0.000342 & 0.000319 & 0.000536 & 0.000517 & 0.000545 & 0.000498 \\
\hline & $P$ & 0.212 & 0.281 & 0.015 & 0.024 & 0.002 & 0.002 \\
\hline & $r$ & -0.214 & -0.185 & -0.411 & -0.383 & -0.520 & -0.512 \\
\hline
\end{tabular}

a by Mann-Whitney- $U$ test, mean normalised transmission with standard deviation (SD) is shown, statistically significant results $(P \leq 0.05)$ are displayed in bold, $r=$ effect size

${ }^{b} n=10$ for $\mathrm{CuSO}_{4}$ and hypericum, $n=12$ for $\mathrm{S}_{8}$

${ }^{c} n=24$ for $\mathrm{CuSO}_{4}$ and $n=25$ for hypericum and $\mathrm{S}_{8}$.

TABLE 2: Comparison ${ }^{a}$ between light transmissions of unexposed potencies $(6 c-30 c)^{b}$ and potencies exposed to external physical factors ${ }^{c}$.

\begin{tabular}{|c|c|c|c|c|c|c|c|}
\hline & \multicolumn{2}{|c|}{$\mathrm{CuSO}_{4}$} & \multicolumn{2}{|c|}{ Hypericum } & \multicolumn{2}{|c|}{$\mathrm{S}_{8}$} \\
\hline & & $190 \mathrm{~nm}-340 \mathrm{~nm}$ & $220 \mathrm{~nm}-340 \mathrm{~nm}$ & $190 \mathrm{~nm}-340 \mathrm{~nm}$ & $220 \mathrm{~nm}-340 \mathrm{~nm}$ & $190 \mathrm{~nm}-340 \mathrm{~nm}$ & $220 \mathrm{~nm}-340 \mathrm{~nm}$ \\
\hline \multirow{2}{*}{ Unexposed } & Mean & 0.999936 & 0.999938 & 0.999834 & 0.999858 & 1.000666 & 1.000593 \\
\hline & SD & 0.000507 & 0.000456 & 0.000761 & 0.000721 & 0.000637 & 0.000602 \\
\hline \multirow{4}{*}{ Autoclave } & Mean & 0.999915 & 0.999943 & 0.999801 & 0.999802 & 1.000557 & 1.000497 \\
\hline & SD & 0.000567 & 0.000517 & 0.000673 & 0.000587 & 0.000563 & 0.000520 \\
\hline & $P$ & 1.000 & 0.738 & 0.857 & 0.669 & 0.451 & 0.590 \\
\hline & $r$ & 0.000 & -0.039 & -0.021 & -0.049 & -0.087 & -0.062 \\
\hline \multirow{4}{*}{ EMF } & Mean & 0.999765 & 0.999779 & 0.999845 & 0.999866 & 1.000661 & 1.000594 \\
\hline & SD & 0.000475 & 0.000423 & 0.000588 & 0.000519 & 0.000715 & 0.000677 \\
\hline & $P$ & 0.237 & 0.256 & 0.787 & 0.787 & 0.973 & 0.982 \\
\hline & $r$ & -0.139 & -0.134 & -0.031 & -0.031 & -0.004 & -0.003 \\
\hline \multirow{4}{*}{ Incubation } & Mean & 0.999629 & 0.999649 & 0.999999 & 1.000009 & 1.000649 & 1.000571 \\
\hline & SD & 0.000431 & 0.000409 & 0.000383 & 0.000334 & 0.000623 & 0.000587 \\
\hline & $P$ & 0.006 & 0.005 & 0.536 & 0.629 & 0.902 & 0.857 \\
\hline & $r$ & -0.322 & -0.331 & -0.071 & -0.056 & -0.014 & -0.021 \\
\hline \multirow{4}{*}{ UV } & Mean & 0.999610 & 0.999637 & 0.999558 & 0.999586 & 1.000676 & 1.000599 \\
\hline & SD & 0.000342 & 0.000319 & 0.000536 & 0.000517 & 0.000545 & 0.000498 \\
\hline & $P$ & 0.001 & 0.001 & 0.029 & 0.033 & 0.973 & 0.928 \\
\hline & $r$ & -0.391 & -0.386 & -0.252 & -0.247 & -0.004 & -0.010 \\
\hline
\end{tabular}

a by Mann-Whitney-U test, mean normalised transmission with standard deviation (SD) is shown, statistically significant results $(P \leq 0.05)$ are displayed in bold, $r=$ effect size.

${ }^{\mathrm{b}}$ Measurements 2 and 3 were combined, since these two measurements were closest in time to the measurements of the exposed samples.

${ }^{c} n=48$ for $\mathrm{CuSO}_{4}$ and $n=50$ for hypericum and $\mathrm{S}_{8}$ (unexposed), $n=24$ for $\mathrm{CuSO}_{4}$ and $n=25$ for hypericum and $\mathrm{S}_{8}$ (exposed).

When every single potency level was compared to the respective controls by Mann-Whitney- $U$ test, only 2 potency levels of the $\mathrm{S}_{8}$ series $(16 \mathrm{c}, 29 \mathrm{c})$ showed a significant difference to the controls after Bonferroni correction for multiple testing (Figure 2(c)).

3.6. Comparison of Previous Works. Table 3 compares previous works of others and our group that investigated hp with UV, visible and/or near infrared light spectroscopy. In Figure 3 , all results from our previous $[23,24]$ and present study are combined.

\section{Discussion}

4.1. Development of Light Spectroscopy Studies. The first studies that investigated hp with light spectroscopy compared whole spectra of hp and controls in mixtures of ethanol and water (Table 3). Zacharias [22] observed differences between hp prepared in pharmacies and under rigorous conditions of cleanness and concluded that changes in the spectra were caused by the introduction of contaminants during preparation. Rao et al. [19] found that the UV spectrum of succussed solvent (ethanol) differed from that of unsuccussed solvent. Korenbaum et al. [17] (comparing homeopathic nosodes and placebos) applied statistical tests in their comparisons and registered distinct wavelengths with significant differences between nosodes and placebos. Works from our group $[23,24]$ introduced series of hp, from 10c to $30 \mathrm{c}$, and compared hp to succussed controls or different potencies of the same original substance. We used water as the solvent and no longer visually compared whole spectra, but applied statistical tests. 


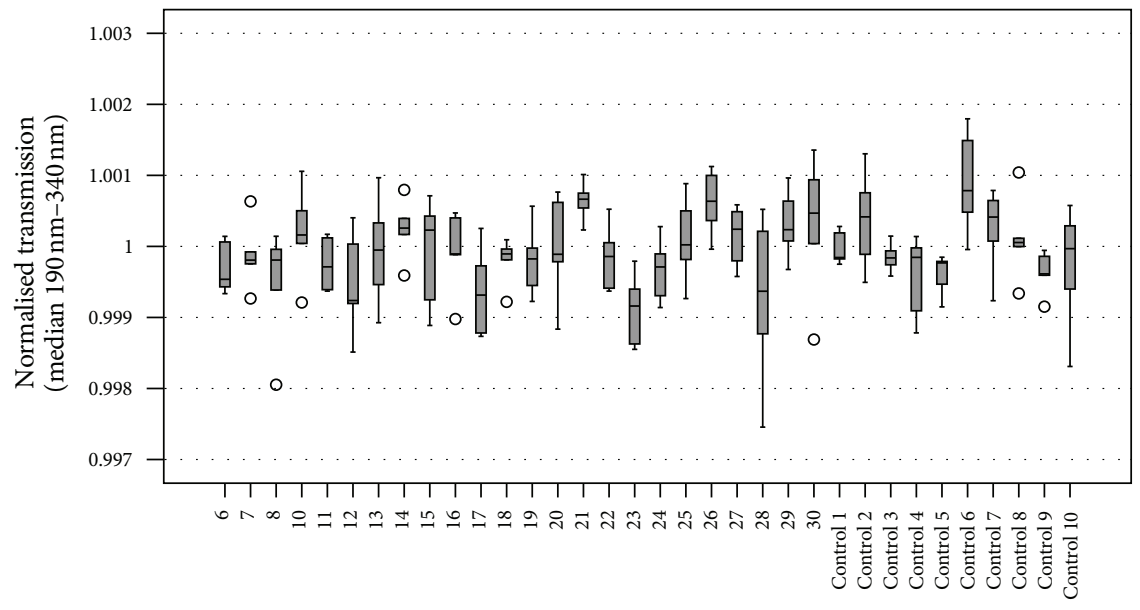

Potency (c)

(a)

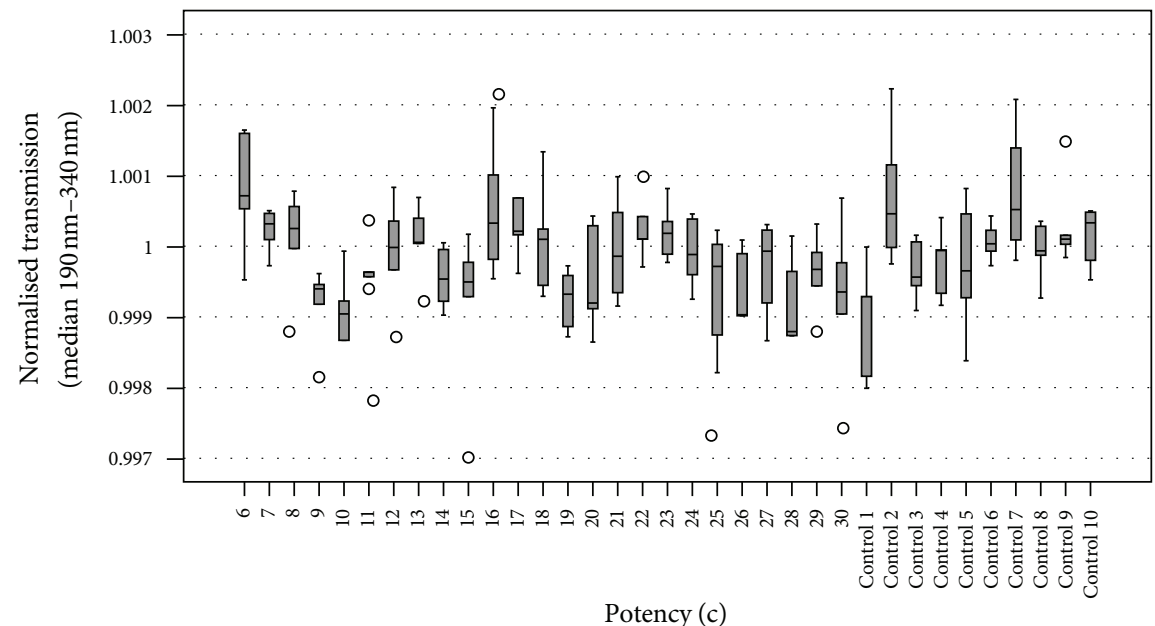

(b)

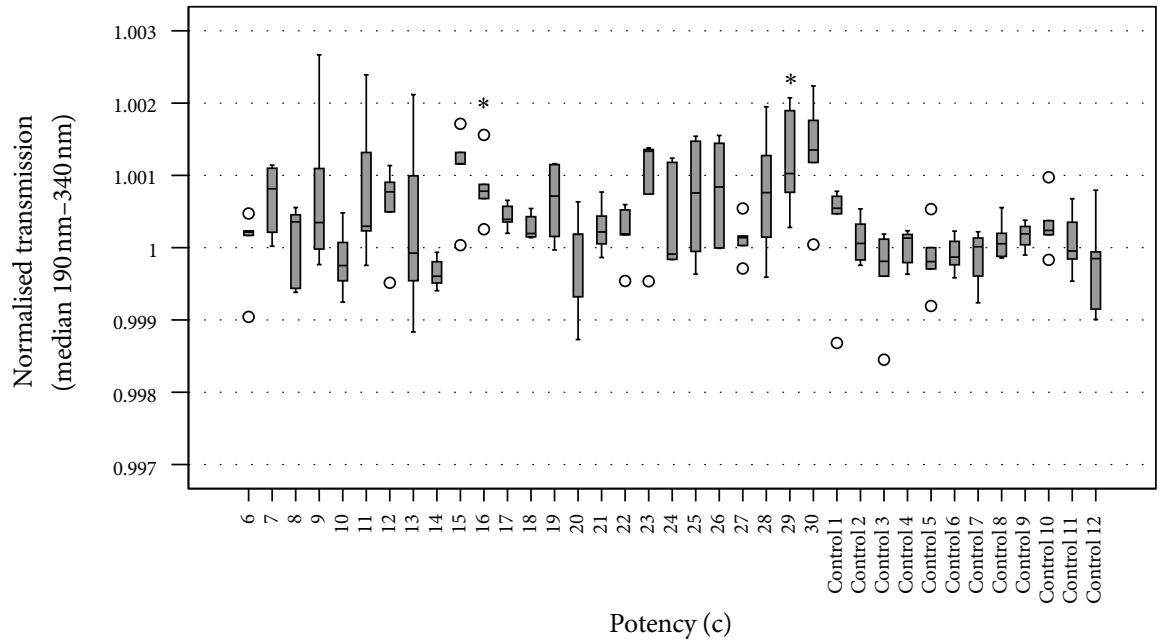

(c)

Figure 2: Boxplots showing light transmissions of potencies and controls (measurements 1 to 5) of $\mathrm{CuSO}_{4}$ (a), hypericum (b), $\mathrm{S}_{8}$ (c). Circles represent outliers (that lie more than one and a half box lengths above or below from the upper or lower quartile, resp.). Every potency level was compared to the combined controls using a Mann-Whitney- $U$ test. Statistically significant results are marked by ${ }^{*}$. Due to multiple testing, $P$ was corrected according to Bonferroni $\left({ }^{*} P \leq 0.05 / 25=0.002\right)$. 


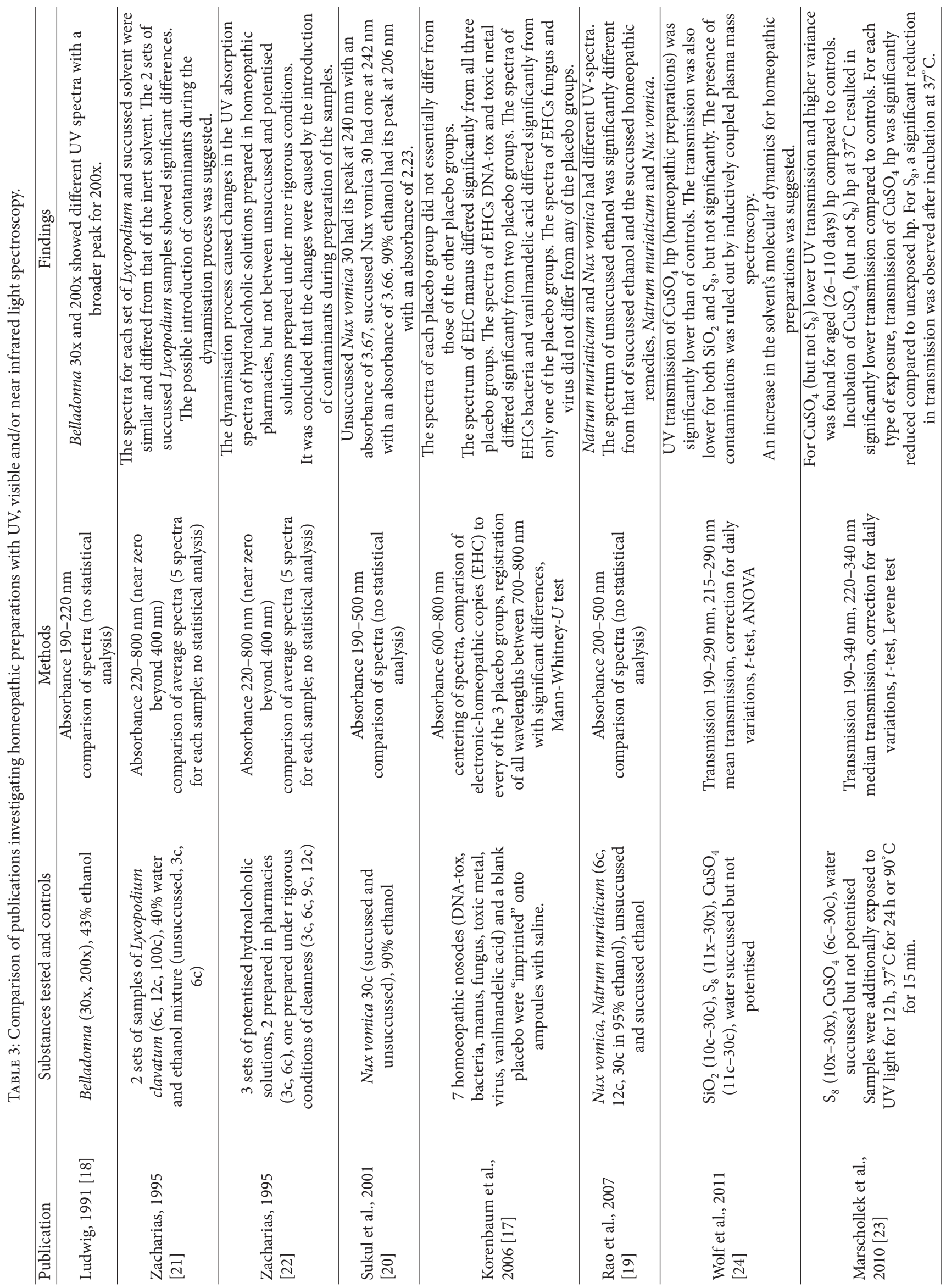




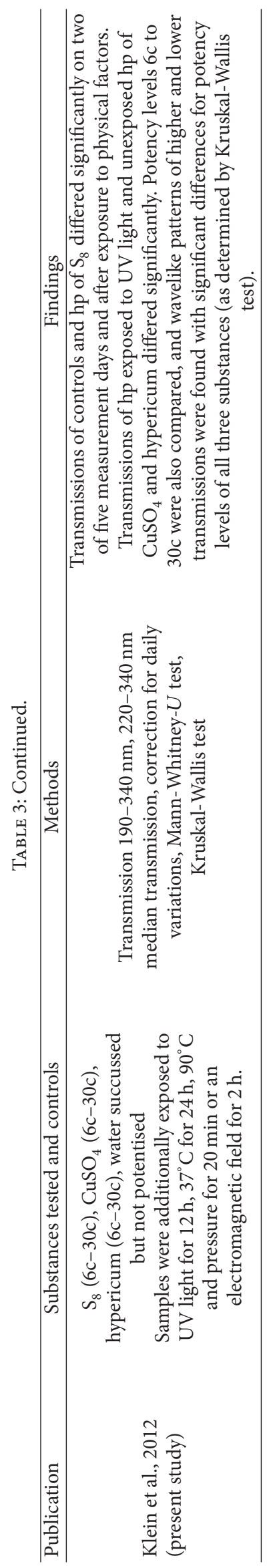




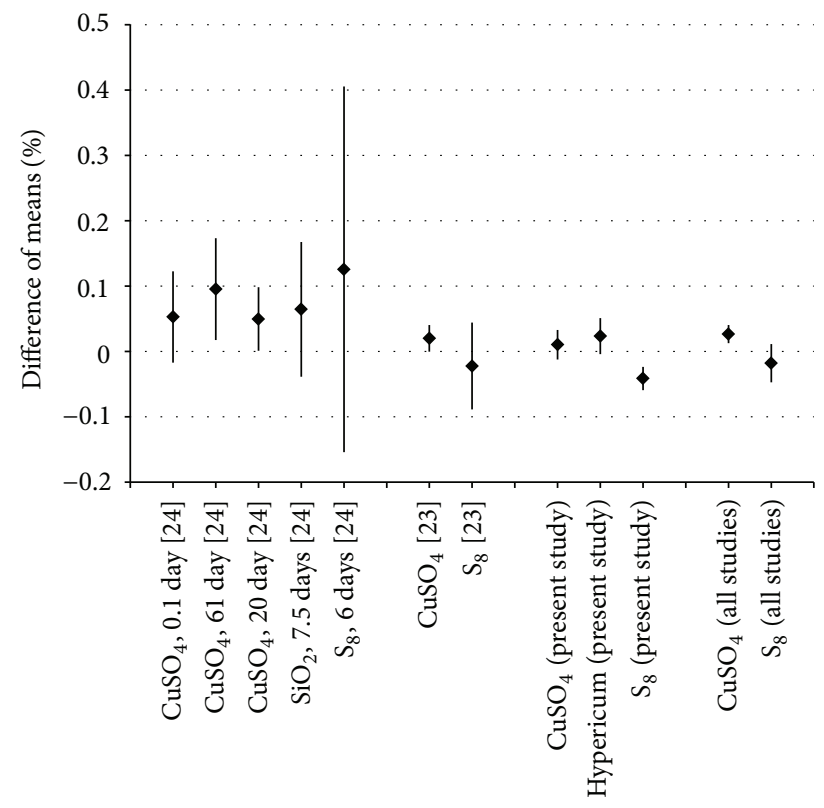

FiguRE 3: Differences of means (transmission of controls - transmission of hp) in \% and 95\% confidence intervals are shown. Previous and the present study are combined for $\mathrm{CuSO}_{4}$ and $\mathrm{S}_{8}$. The studies are weighed according to the number of measurement days, that is, 1 for [24], 6 for [23], and 5 for the present study.

4.2. Reproducibility of Our Experiments. Difficulties in reproducing experimental results are sometimes used as arguments against specific actions of hp. In the present study, we investigated UV transmissions of hp for the third time. In the first study, hp of $\mathrm{CuSO}_{4}$ were found to have significantly lower UV transmissions than controls [24]. In the second study, slightly aged but not fresh hp of $\mathrm{CuSO}_{4}$ were found to have significantly lower UV transmissions than controls [23]. No differences were found between decimal serial dilutions of $\mathrm{S}_{8}$ and controls in either of these two studies.

For the present (third) study, modifications in the experimental setup and data analysis were made: the samples were not measured immediately after production (because in earlier studies, no significant differences could be observed at that time point), centesimal instead of decimal dilutions of $\mathrm{S}_{8}$ were prepared (to enable a comparison between different substances but of the same dilution category), and non-parametric statistical tests were used. Now significant differences between hp of $\mathrm{S}_{8}$ (but not of $\mathrm{CuSO}_{4}$ ) and controls were found. In both the second and third study, incubation to $37^{\circ} \mathrm{C}$ for $24 \mathrm{~h}$ led to differences between hp of $\mathrm{CuSO}_{4}$ and controls, and exposure of hp to $37^{\circ} \mathrm{C}$ or UV radiation led to reduced transmissions compared to non-exposed hp.

$\mathrm{Hp}$ of $\mathrm{S}_{8}$ had higher transmissions than controls, unlike hp of $\mathrm{CuSO}_{4}$ and hypericum. In the present study, we investigated centesimal potencies of $S_{8}\left(S_{8} c\right)$ in contrast to decimal potencies in earlier studies in order to be able to compare centesimal potencies of different starting substances. Therefore, it may well be to that we obtained different results because $\mathrm{S}_{8} \mathrm{c}$ may exhibit different features than $\mathrm{S}_{8} \mathrm{x}$. In fact, in clinical use for some substances, such as sulfur and phosphor reciprocal effects depending on the potency level are known. If lower transmission was an indicator of a less structured state, higher transmission could be an indicator of a more structured state of the $S_{8}$ hp. Additionally, in one of our previous studies [23], $\mathrm{S}_{8}$ also showed a different behaviour than $\mathrm{CuSO}_{4}$ : when exposed to external factors, the variance of $\mathrm{CuSO}_{4}$ hp was increased, whereas the opposite was the case for $\mathrm{S}_{8}$.

Overall, hp and controls showed comparable differences in these three studies, indicating specific characteristics of hp. When these studies are combined, hp of $\mathrm{CuSO}_{4}$ have significantly lower transmissions than controls. Heat and ageing seem not only to change the physical properties of hp, but also their efficacy, as observed in a wheat germination model [37].

4.3. Possibility of Contaminations in hp. Earlier publications by other groups suggested contaminations to occur during the potentisation process $[21,22,38]$. In one of our previous studies, however, we showed that hp can be prepared with a minimum of inorganic contaminants, and differences in transmission of hp and controls are not due to contaminants [24]. According to the conclusions of a previous study [30], importance was attached in the experiments presented in this article to the cleaning of the bottles, the preparation of hp and controls (handling under a laminar flow, potentisation with water only, controls were succussed but not potentised) as well as the storage conditions (equal for hp and controls).

4.4. Models Assume Changes in Water Structure. So far, several models have been proposed to explain the different properties of hp and controls, including supramolecular states of dissolved gases and hydrogen-bonded supramolecular water structures [31] or dynamisation [30]. Most models assume 
the absence of traces of the starting material and focus on water structure, although it was reported that nanoparticles of metal starting materials may be found in high potencies [39]. Important questions remain how various starting materials can give rise to distinguishable physicochemical properties of the hp, for example the response to external physical factors that differed between $\mathrm{CuSO}_{4}$, hypericum and $\mathrm{S}_{8}$ in our experiments. It is a common criticism about homeopathic remedies, that if water had a memory of the original substances it came in contact with, it would be full of memories and would exert unpredictable effects $[1,4]$. However, it has been shown that exposure of hp to external physical factors may reverse the properties of hp towards the properties of the solvents [31].

4.5. Limitations of This Work. Since the UV spectrophotometer was calibrated before each measurement series, there were small differences in the level of the absolute transmission values (in the order of $<1 \%$ ). These daily differences affected the controls and hp in the same way and are therefore not the reason for differences between controls and hp. As can be seen in Figure 2(a), not only the potency levels of $\mathrm{CuSO}_{4}$ showed variations in transmission, but also the controls deviated from each other. This may be the reason why the differences shown in previous studies between hp and controls of $\mathrm{CuSO}_{4}[23,24]$ were not found in this study. Further differences were the person producing and measuring the hp and controls, as well as the location of the production and measurement. Exposures to external physical factors were done only once per factor (autoclave, EMF, incubation at $37^{\circ} \mathrm{C}$, UV light) and per starting material $\left(\mathrm{CuSO}_{4}\right.$, hypericum, $S_{8}$ ) due to the limited total amount of our hp samples. In future studies repeating of exposure should be considered to obtain more indicative results. Additionally, it would be worthwhile investigating in future studies how repetitive exposure to physical factors would affect the results.

Trivial artefacts such as a cause for the differences between homeopathic preparations and controls can be ruled out due to the rigorous study design including randomisation and blinding of the samples.

\section{Conclusions}

This study confirmed and expanded some of our previous findings. By demonstrating differences in UV transmission between hp and controls, the study contributes to the understanding of physical properties of hp. It also shows that hp are not inert to for example heat and UV light and that their properties may change, which might be relevant for production, storage, and handling of hp.

\section{Conflict of Interests}

The authors declare that they have no conflict of interests.

\section{Acknowledgments}

The study was supported by a Laboratory Material Grant by the Karl and Veronica Carstens-Stiftung (Essen, Germany).
The starting material was provided by the respective companies.

\section{References}

[1] K. Smith, "Against homeopathy-a utilitarian perspective," Bioethics, vol. 26, no. 8, pp. 398-409.

[2] L. Milgrom and K. Chatfield, "Is homeopathy really "morally and ethically unacceptable"? A critique of pure scientism," Bioethics, vol. 26, no. 9, pp. 501-503, 2012.

[3] R. Moskowitz, "For homeopathy: a practising physician's perspective," Bioethics, vol. 26, no. 9, pp. 499-500, 2012.

[4] K. Smith, "Homeopathy is unscientific and unethical," Bioethics, vol. 26, no. 9, pp. 508-512, 2012.

[5] L. Rutten, R. T. Mathie, P. Fisher, M. Goossens, and M. van Wassenhoven, "Plausibility and evidence: the case ofhomeopathy," Medicine, Health Care and Philosophy. In press.

[6] C. M. Witt, M. Bluth, H. Albrecht, T. E. R. Weißhuhn, S. Baumgartner, and S. N. Willich, "The in vitro evidence for an effect of high homeopathic potencies-A systematic review of the literature," Complementary Therapies in Medicine, vol. 15, no. 2, pp. 128-138, 2007.

[7] V. Majewsky, S. Arlt, D. Shah et al., "Use of homeopathic preparations in experimental studies with healthy plants," Homeopathy, vol. 98, no. 4, pp. 228-243, 2009.

[8] G. Bornhöft, U. Wolf, K. Von Ammon et al., "Effectiveness, safety and cost-effectiveness of homeopathy in general practice-summarized health technology assessment," Forschende Komplementarmedizin, vol. 13, no. 2, pp. 19-29, 2006.

[9] H. Frei, R. Everts, K. Von Ammon et al., "Homeopathic treatment of children with attention deficit hyperactivity disorder: a randomised, double blind, placebo controlled crossover trial," European Journal of Pediatrics, vol. 164, no. 12, pp. 758-767, 2005.

[10] J. Jacobs, L. M. Jiménez, S. Malthouse et al., "Homeopathic treatment of acute childhood diarrhea: results from a clinical trial in Nepal," Journal of Alternative and Complementary Medicine, vol. 6, no. 2, pp. 131-139, 2000.

[11] D. T. Reilly, M. A. Taylor, C. McSharry, and T. Aitchison, "Is homoeopathy a placebo response? Controlled trial of homoeopathic potency, with pollen in hayfever as model," The Lancet, vol. 2, no. 8512, pp. 881-886, 1986.

[12] D. Reilly, M. A. Taylor, N. G. M. Beattie et al., "Is evidence for homoeopathy reproducible?" The Lancet, vol. 344, no. 8937, pp. 1601-1606, 1994.

[13] J. Kleijnen, P. Knipschild, and G. Ter Riet, "Clinical trials of homoeopathy," British Medical Journal, vol. 302, no. 6772, pp. 316-323, 1991.

[14] K. Linde, N. Clausius, G. Ramirez et al., "Are the clinical effects of homoeopathy placebo effects? A meta-analysis of placebocontrolled trials," The Lancet, vol. 350, no. 9081, pp. 834-843, 1997.

[15] M. Cucherat, M. C. Haugh, M. Gooch, and J. P. Boissel, "Evidence of clinical efficacy of homeopathy. A meta-analysis of clinical trials," European Journal of Clinical Pharmacology, vol. 56, no. 1, pp. 27-33, 2000.

[16] C. Becker-Witt, T. E. R. Weißhuhn, R. Lüdtke, and S. N. Willich, "Quality assessment of physical research in homeopathy," Journal of Alternative and Complementary Medicine, vol. 9, no. 1, pp. 113-132, 2003. 
[17] V. I. Korenbaum, T. N. Chernysheva, T. P. Apukhtina, and L. N. Sovetnikova, "Absorption spectra of electronic-homoeopathic copies of homoeopathic nosodes and placebo have essential differences," Forschende Komplementarmedizin, vol. 13, no. 5, pp. 294-297, 2006.

[18] W. Ludwig, "Physikalische grundlagenforschung in bezug auf informationsspeicherung in lebenden systemen und homöopathischen medikamenten," Erfahrungsheilkunde, vol. 4, pp. 293-295, 1991.

[19] M. L. Rao, R. Roy, I. R. Bell, and R. Hoover, "The defining role of structure (including epitaxy) in the plausibility of homeopathy," Homeopathy, vol. 96, no. 3, pp. 175-182, 2007.

[20] N. C. Sukul, A. De, R. Dutta, A. Sukul, and S. P. Sinhababu, "Nux vomica 30 prepared with and without succussion shows antialcoholic effect on toads and distinctive molecular association," British Homeopathic Journal, vol. 90, no. 2, pp. 79-85, 2001.

[21] C. R. Zacharias, "Contaminants in commercial homoeopathic medicines. A spectroscopic determination," British Homoeopathic Journal, vol. 84, no. 2, pp. 71-74, 1995.

[22] C. R. Zacharias, "Implications of contaminants to scientific research in homoeopathy," British Homoeopathic Journal, vol. 84, no. 1, pp. 3-5, 1995.

[23] B. Marschollek, M. Nelle, M. Wolf, S. Baumgartner, P. Heusser, and U. Wolf, "Effects of exposure to physical factors on homeopathic preparations as determined by ultraviolet light spectroscopy," TheScientificWorldJournal, vol. 10, pp. 49-61, 2010.

[24] U. Wolf, M. Wolf, P. Heusser, A. Thurneysen, and S. Baumgartner, "Homeopathic preparations of quartz, sulfur and copper sulfate assessed by UV-spectroscopy," Evidence-Based Complementary and Alternative Medicine, vol. 2011, Article ID 692798, 11 pages, 2011.

[25] O. Weingärtner, "NMR-features that relate to homoeopathic sulphur-potencies," Berlin Journal on Research in Homoeoepathy, vol. 1, no. 1, pp. 61-68, 1990.

[26] J. L. Demangeat, C. Demangeat, P. Gries, B. Poitevin, and A. Constantinesco, "Modifications des temps de relaxation RMN á $4 \mathrm{MHz}$ des protons du solvant dans les très hautes dilutions salines de silice/lactose," Journal De MéDecine Nucléaire Et Biophysique, vol. 16, pp. 135-145, 1992.

[27] J. L. Demangeat, P. Gries, B. Poitevin et al., "Low-field NMR water proton longitudinal relaxation in ultrahighly diluted aqueous solutions of silica-lactose prepared in glass material for pharmaceutical use," Applied Magnetic Resonance, vol. 26, no. 4, pp. 465-481, 2004.

[28] S. Aabel, S. Fossheim, and F. Rise, "Nuclear magnetic resonance (NMR) studies of homeopathic solutions," British Homeopathic Journal, vol. 90, no. 1, pp. 14-20, 2001.

[29] D. J. Anick, "High sensitivity ${ }^{1} \mathrm{H}-\mathrm{NMR}$ spectroscopy of homeopathic remedies made in water," BMC Complementary and Alternative Medicine, vol. 4, article 15, 2004.

[30] S. Baumgartner, M. Wolf, P. Skrabal et al., "High-field ${ }^{1} \mathrm{H}$ $\mathrm{T}_{1}$ and $\mathrm{T}_{2}$ NMR relaxation time measurements of $\mathrm{H}_{2} \mathrm{O}$ in homeopathic preparations of quartz, sulfur, and copper sulfate," Naturwissenschaften, vol. 96, no. 9, pp. 1079-1089, 2009.

[31] J. L. Demangeat, "NMR water proton relaxation in unheated and heated ultrahigh aqueous dilutions of histamine: evidence for an air-dependent supramolecular organization of water," Journal of Molecular Liquids, vol. 144, no. 1-2, pp. 32-39, 2009.

[32] V. Elia and M. Niccoli, "New physico-chemical properties of water induced by mechanical treatments. A calorimetric study at $25^{\circ} \mathrm{C}$," Journal of Thermal Analysis and Calorimetry, vol. 61, no. 2, pp. 527-537, 2000.

[33] L. Rey, "Thermoluminescence of ultra-high dilutions of lithium chloride and sodium chloride," Physica A, vol. 323, pp. 67-74, 2003.

[34] R. Van Wijk, S. Bosman, and E. P. A. Van Wijk, "Thermoluminescence in ultra-high dilution research," Journal of Alternative and Complementary Medicine, vol. 12, no. 5, pp. 437-443, 2006.

[35] Homöopathisches Arzneibuch (HAB, 2009), Deutscher Apotheker, Stuttgart, Germany, 2009.

[36] A. Field, Discovering Statistics Using SPSS, Sage PublicationsNew Delhi, Washington, DC, USA, 3rd edition, 2009.

[37] M. Brizzi, V. Elia, G. Trebbi, D. Nani, M. Peruzzi, and L. Betti, "The efficacy of ultramolecular aqueous dilutions on a wheat germination model as a function of heat and aging-time," Evidence-Based Complementary and Alternative Medicine, vol. 2011, Article ID 696298, 11 pages, 2011.

[38] C. M. Witt, R. Lüdtke, T. E. R. Weißhuhn, P. Quint, and S. N. Willich, "The role of trace elements in homeopathic preparations and the influence of container material, storage duration, and potentisation," Forschende Komplementarmedizin, vol. 13, no. 1, pp. 15-21, 2006.

[39] P. S. Chikramane, A. K. Suresh, J. R. Bellare, and S. G. Kane, "Extreme homeopathic dilutions retain starting materials: a nanoparticulate perspective," Homeopathy, vol. 99, no. 4, pp. 231-242, 2010. 


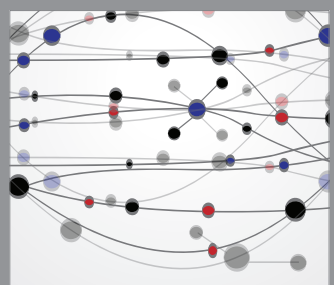

The Scientific World Journal
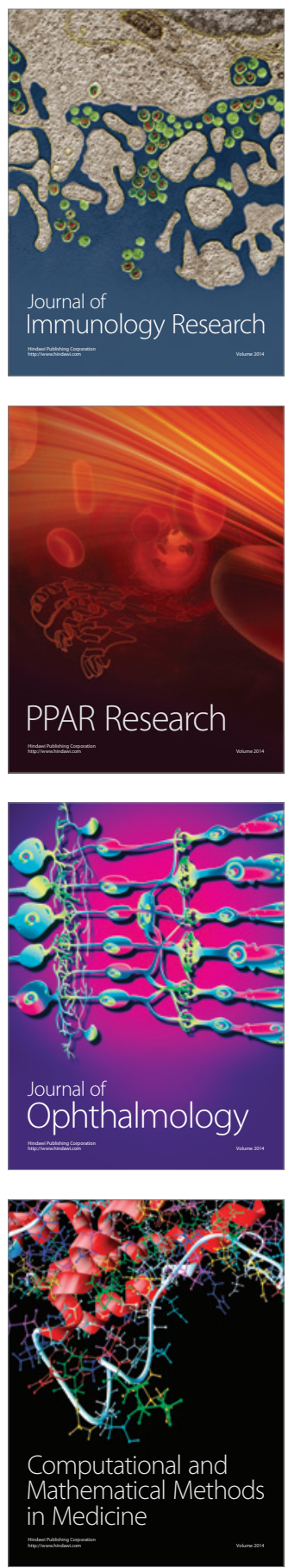

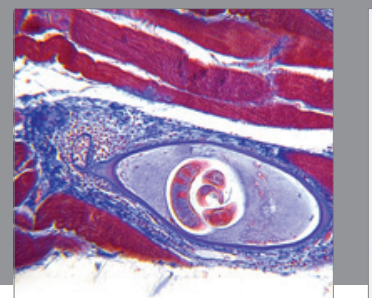

Gastroenterology

Research and Practice
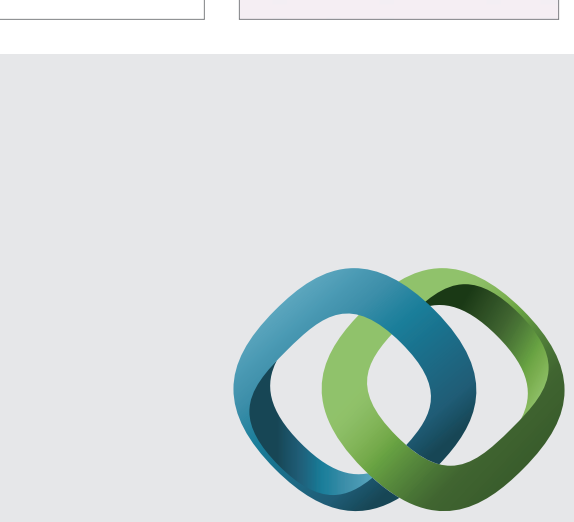

\section{Hindawi}

Submit your manuscripts at

http://www.hindawi.com
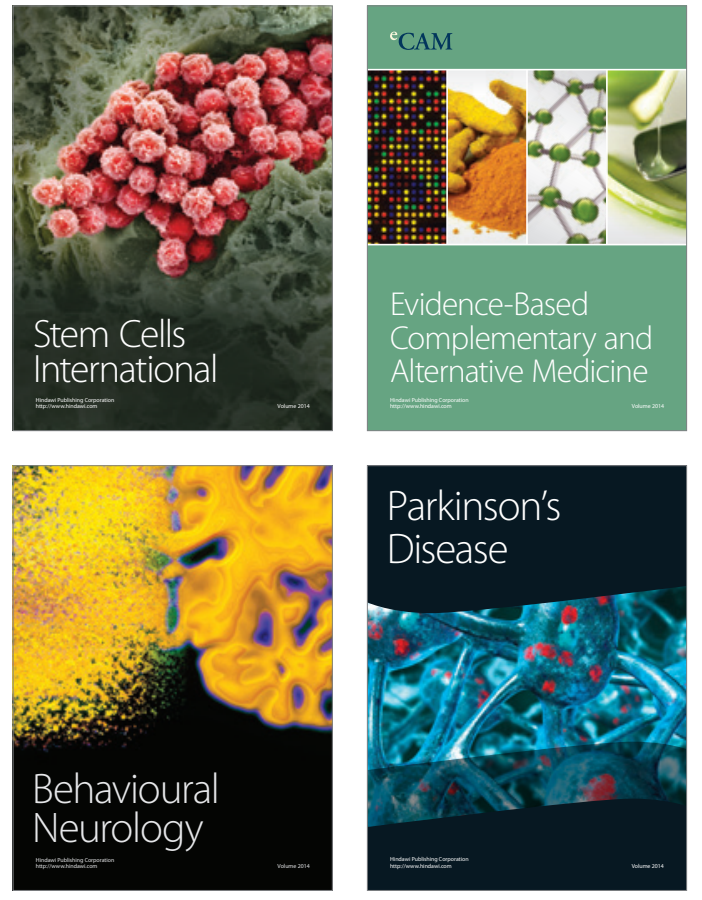
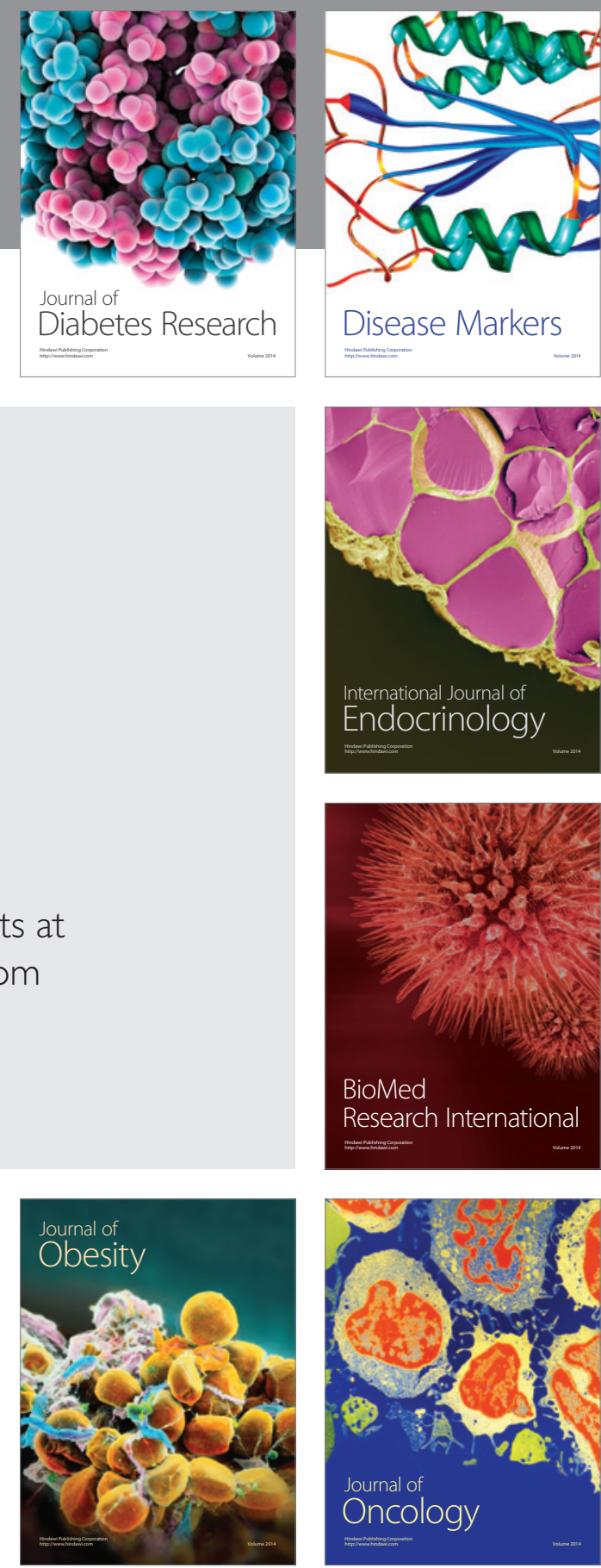

Disease Markers
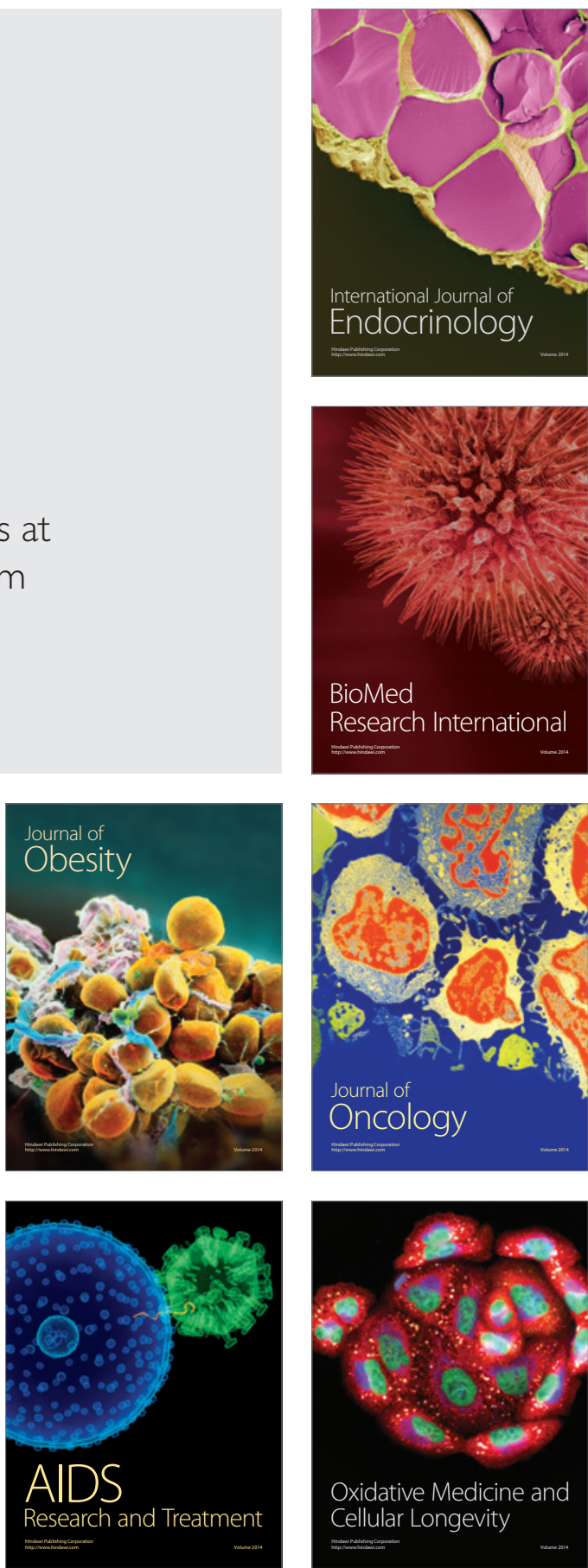